\title{
Use of phosphatidylcholine in Tris-based extender with or without egg yolk to freeze Bapedi ram semen
}

\author{
K.S. Mafolo ${ }^{1,2}$, C.M. Pilane ${ }^{1}$, T. Chitura2 ${ }^{2}$ T.L. Nedambale ${ }^{1,3 \#}$ \\ ${ }^{1}$ Agricultural Research Council, Germplasm Conservation and Reproductive Biotechnology, Irene, South Africa \\ 2 University of Limpopo, Department of Animal Production and Agricultural Economics, Sovenga, South Africa \\ ${ }^{3}$ Tshwane University of Technology, Department of Animal Sciences, Pretoria, South Africa
}

(Submitted 9 September 2019; Accepted 4 January 2020; First published online 16 June 2020)

\begin{abstract}
Copyright resides with the authors in terms of the Creative Commons Attribution 4.0 South African Licence.
See: http://creativecommons.org/licenses/by/4.0/za

Conditions of use: The user may copy, distribute, transmit and adapt the work, but must recognise the authors and the South African Journal of Animal Science.
\end{abstract}

\begin{abstract}
Traditionally, egg yolk is a protective agent that is used to freeze semen in various species. However, the addition of egg yolk in extender risks the introduction of disease. Therefore, an alternative cryoprotective agent should be found to preserve ram semen. The aim of this study was to evaluate the effect of phosphatidylcholine (PC) as a protective agent in extender with or without egg yolk on semen characteristics and acrosome integrity of frozen then thawed Bapedi ram semen. Semen was collected from four mature Bapedi rams, in the Agricultural Research Council (ARC) Germplasm Conservation Programme, using an artificial vagina. Following collection, semen samples were randomly diluted into Tris-based extender (1:2), with and without egg yolk, and supplemented with four concentrations of PC liposome $(0 \mathrm{mg} / \mathrm{ml}), 0.25 \mathrm{mg} / \mathrm{ml}$, $0.5 \mathrm{mg} / \mathrm{ml}$ and $0.75 \mathrm{mg} / \mathrm{ml}$ ). Supplementation of PC liposome in extender with or without egg yolk did not improve the semen total motility (TM), progressive motility (PM) and rapid motility (RM) rate. The sperm cell membrane integrity in extender with or without egg yolk was not influenced by the supplementation of PC liposome after thawing $(P>0.05)$. The addition of $P C$ liposome to Tris-based extender with egg yolk had a similar result to control (Tris-based extender with egg yolk) on sperm cell acrosome integrity. In conclusion, supplementation of PC liposome to Tris-based extender without egg yolk had lower sperm cell viability and motility rates compared with the extender with egg yolk, regardless of concentration.
\end{abstract}

\footnotetext{
Keywords: acrosome, cryoprotectant, liposome, membrane, motility

\#Corresponding author: NedambaleTL@tut.ac.za
}

\section{Introduction}

Cryopreservation of semen is a useful technology for indefinite conservation of spermatozoa and preservation of genetic resources (Day \& Stacey, 2007; Castro et al., 2016). However, cryopreservation can be detrimental to the structure of the sperm plasma membrane (Chelucci et al., 2015; El-Sisy et al., 2016; Khalil et al., 2018), which is regarded as the major site of damage (Khan \& ljaz, 2008; Fang et al., 2016) because of the release of phospholipids to the surrounding medium as a result of cold shock (Ropke et al., 2011; Castro et al., 2016). The lipid composition of the sperm membrane is essential to maintaining viability of the spermatozoa during cryopreservation (Forouzanfar et al., 2010; Castro et al., 2016). Loss of lipids from the sperm membrane compromises the motility of the sperm cells (Matsuoka et al., 2006; RodriguezMartinez \& Barth, 2007) and the integrity of their acrosome, resulting in low fertility (Hernandez et al., 2012; Alcay et al., 2016). Phosphatidylcholine is one of the major phospholipids in spermatozoa (Ricker et al., 2006; Zhang et al., 2009; Fang et al., 2016).

Egg yolk is a reliable cryoprotective component of the extender that is used when freezing semen owing to its ability to protect the spermatozoa against cold shock (Amirat et al., 2004; Kulaksiz et al., 2010; Dong et al., 2011; Toker et al., 2016). However, its use has been disputed because of the risk of introducing disease (Chelucci et al., 2015) and owing to inconsistency in its biochemical composition (Kulaksiz et al., 2010; Emamverdi et al., 2013). Additionally, it may inhibit sperm metabolism and respiration, reduce motility, and cause difficulties during semen analysis (Amirat et al., 2004; Singh et al., 2012; Ugur et al., 2019). Therefore, the discovery of a substitute that allows the partial or complete replacement of egg yolk as a 
component of the extender that is used when freezing semen is warranted. Previous studies that were aimed at finding replacements for egg yolk produced conflicting results, some with favourable outcomes (Forouzanfar et al., 2010; Emamvardi et al., 2013; Vidal et al., 2013; Ustuner et al., 2014; Jerez et al., 2016) and some unfavourable (Jeyendran et al. 2008; Najafi et al., 2014). For example, soybean PC reportedly inhibited the mitochondrial activities of the spermatozoa (Del Valle et al., 2012) and was less phospholipid than egg yolk (Jeyendran et al. 2008).

The major cryoprotective agent for sperm cells in egg yolk is reportedly PC (Bergeron \& Manjunath, 2006; Forouzanfar et al., 2010). The introduction or supplementation of liposomal PC in extenders improved the outcomes of cryopreserved semen of bulls (Ropke et al., 2011), boars (Alvarez-Rodriguez et al., 2017), dogs (Belala et al., 2016), buffalo (Kumar et al., 2015) and stallions (Pillet et al., 2012). Liposomes are vesicular structures made of phospholipids in aqueous solution, arising from lipid bilayers organized concentrically, similar to biological membranes (Grad, 2010). Murphy et al. (2018) and Luna-Orozco et al. (2019) studied the effects of unspecified liposome and egg yolk based extenders in bull and ram semen, respectively. However, current information on ram semen cryopreservation using PC liposome in extender is limited. Supplementation of PC liposome in extenders with a reduced concentration of egg yolk might be advantageous in reducing the potential for disease transmission because they can be prepared from lipids that are free from infectious vectors and microbial contaminants (Kumar et al., 2015). Therefore, the aim of this study was to evaluate the effect of PC as a cryoprotectant in extender with or without egg yolk on semen characteristics and acrosome integrity of sperm cells in semen from Bapedi rams that had been frozen and then thawed.

\section{Materials and Methods}

The Animal Ethics Committee of the Agricultural Research Council (ARC) approved the study prior to its commencement (Ref no APIEC15/048 of 2016). The study was conducted at the laboratory of the ARC Germplasm Conservation and Reproductive Biotechnologies, Irene ( $\left.25^{\circ} 55^{\prime} \mathrm{S} ; 2^{\circ} 12^{\prime} \mathrm{E}\right)$, Pretoria, South Africa.

Semen that were used in this study were produced by four healthy and sexually mature Bapedi rams with good body conformation, well-developed testes and good vigour. The rams had an average bodyweight and scrotal circumference of $54.5 \pm 2.25 \mathrm{~kg}$ and $31.8 \pm 0.85 \mathrm{~cm}$, respectively. They had good libido and had been adapted previously to the use of an artificial vagina for semen collection. The rams were kept separately and fed Panicum maximum hay supplemented with sheep pellets (Meadow, Johannesburg, South Africa). Water was provided ad libitum. A total of 16 ejaculates were collected one per week for four consecutive weeks during the breeding season from April to May.

All chemicals were purchased from Sigma-Aldrich® (St. Louis, Missouri, USA), unless otherwise stated. The Tris-based extender consisted of $3.63 \mathrm{~g}$ Tris (hydroxymethylaminoethane), $1.99 \mathrm{~g}$ citric acid, $0.05 \mathrm{~g}$ gentamycin sulphate and $0.5 \mathrm{~g}$ fructose in $100 \mathrm{~mL}$ distilled water (fraction A). Glycerol was added to an aliquot of this extender at $7.0 \% \mathrm{v} / \mathrm{v}$ (fraction B). Fraction $\mathrm{A}$ was supplemented in a $2 \times 4$ factorial arrangement of treatments with and without $10 \%(\mathrm{v} / \mathrm{v})$ egg yolk, and with PC at $0,0.25,0.50,0.75 \mathrm{mg} / \mathrm{ml}$. The PC was prepared by the extrusion method from lyophilized egg yolk PC (P3556, Sigma-Aldrich) to create PC liposome (Ropke et al., 2011; Long \& Conn, 2012). Each of the eight treatments was replicated four times using pooled semen from the four rams. All semen extenders were prepared on the day before semen collection and incubated in a water bath at $37^{\circ} \mathrm{C}$. Semen processing and cryopreservation followed Munyai (2014) with a minor modification. Only samples with sperm that was greater than $75 \%$ were used. The pooled semen samples were diluted with fraction $A$ extender at $37{ }^{\circ} \mathrm{C}$ at a ratio of $1: 2$ and then transferred to a walk-in refrigerator at $5^{\circ} \mathrm{C}$, together with fraction $\mathrm{B}$. After two hours, fraction $\mathrm{B}$ was slowly added to semen that had previously been extended with fraction $A$ at same ratio (1:2). The extended semen samples were loaded into $0.25 \mathrm{ml}$ plastic straws (IMV ${ }^{\circledR}$ Technologies, L'Aigle Cedex, France) and sealed with dry polyvinyl powder. The sealed straws were equilibrated in a walk-in refrigerator at $5^{\circ} \mathrm{C}$ for another two hours, then frozen in a programmable freezer (CBS Scientific, California, United States) at these rates: 3 ${ }^{\circ} \mathrm{C} / \mathrm{min}$ from $5{ }^{\circ} \mathrm{C}$ to $-8{ }^{\circ} \mathrm{C}$, and from $-8^{\circ} \mathrm{C}$ to $-120^{\circ} \mathrm{C}$ at $15^{\circ} \mathrm{C} /$ min (Alcay et al., 2015). The frozen semen straws were plunged into a liquid nitrogen tank $\left(-196{ }^{\circ} \mathrm{C}\right)$ and stored for one month before thawing and evaluation.

Prior to evaluation, two replicate straws from each treatment were thawed by immersion in a water bath at $37^{\circ} \mathrm{C}$ for 30 seconds. Each straw was then dried with a paper towel and cut open with clean scissors. The semen was transferred to a dry $1.5 \mathrm{~mL}$ Eppendorf tube and maintained at $37^{\circ} \mathrm{C}$.

Motility was assessed with the computer-aided sperm analysis (CASA) system of Sperm Class Analyzer ${ }^{\circledR}$ SCA $^{\circledR}$ V.5.3 (Animal/Veterinary Microptic S.L, Barcelona, Spain). Briefly, $5 \mu \mathrm{L}$ of semen was diluted with $100 \mu \mathrm{L}$ of Tris buffer in a microcuvette at $37^{\circ} \mathrm{C}$. The settings for sperm image analyses were brightness (166), chamber (cover slide), circular (50\% linearity), connectivity (12), contrast (450), optics (Ph-) 
number of images (50), images per second (50), particle area (15 - $70 \mu \mathrm{m} 2)$, progressivity (80\% STR), scale (10x), slow (VAP of $0-30 \mu \mathrm{m} / \mathrm{s}$ ), medium (VAP of 30-80 $\mu \mathrm{m} / \mathrm{s}$ ) andrapid (> VAP of $80 \mu \mathrm{m} / \mathrm{s}$ ), and velocity on the average path points (7). The $5 \mu \mathrm{L}$ of diluted semen was pipetted onto the microscope glass slide and covered gently with a microscope cover slip. The sperm cells were evaluated under 10x magnification with the SCA ${ }^{\circledR}$ microscope (Nikon, China) projecting an image on a monitor, and captured with a video camera (Caméra Digital Basler A312, Germany). For each sample, more than three fields per drop were analysed and a minimum of 200 sperm were evaluated. The percentage of total motile sperm cells, progressive motility (\%), curvilinear velocity (VCL), linear velocity (VSL), and mean velocity (VAP) ( $\mu \mathrm{m} / \mathrm{s})$ were evaluated.

To assess sperm cell morphology, the percentage of live sperm cells and abnormalities were evaluated using eosin-nigrosin staining according to the protocol of Munyai (2012). Briefly, $5 \mu \mathrm{L}$ of semen was diluted in $20 \mu \mathrm{L}$ of eosin-nigrosin staining, and $7 \mu \mathrm{L}$ of the dilution was pipetted and smeared on a glass slide and evaluated after drying at room temperature. The slides were placed on a microscope table and a drop of immersion oil was placed on the slide to evaluate live, dead and abnormal spermatozoa with a fluorescent microscope (Olympus Corporation BX 51FT, Tokyo, Japan) under 100x magnification. A total of 200 spermatozoa per slide were evaluated and the total spermatozoa abnormalities were recorded.

Integrity of the sperm cell membrane was evaluated using a hypo-osmotic swelling test (HOST) solution prepared with $9 \mathrm{~g}$ fructose and $4.9 \mathrm{~g}$ sodium citrate per litre distilled water (Alcay et al., 2015). Briefly, $10 \mu \mathrm{L}$ semen was diluted with $100 \mu \mathrm{L} \mathrm{HOST}$ solution and incubated at $37^{\circ} \mathrm{C}$ for 60 minutes. After incubation, $20 \mu \mathrm{L}$ diluted semen was spread on a warm slide $\left(37^{\circ} \mathrm{C}\right)$ and covered with a cover slip. For evaluation, 200 sperm cells were counted under 1000x magnification using a phase-contrast microscope. Sperm cells with swollen or coiled tails were recorded as intact and those with curled tails as damaged.

Sperm cell acrosome integrity was evaluated with Pisum sativum agglutinin fluorescein conjugate (PSA-FITC) according to the protocols of Alcay et al. (2015). Five $\mu \mathrm{L}$ of Bapedi ram semen was diluted with $200 \mu \mathrm{L}$ Tris-buffer. Then $20 \mu \mathrm{L}$ diluted semen was re-suspended in $500 \mu \mathrm{L}$ phosphate buffered saline (PBS) and centrifuged at $2000 \mathrm{rpm}$ for 20 minutes. The supernatant was discarded, and the semen pellet was resuspended in $250 \mu \mathrm{L}$ PBS solution. One drop of re-suspended semen was smeared on a glass microscope slide and air dried. Then the slides were fixed with acetone at $4{ }^{\circ} \mathrm{C}$ for 10 minutes and covered with PSAFITC solution ( $50 \mu \mathrm{g} / \mathrm{mL}$ in PBS solution) in dark room for 30 minutes. The slides were rinsed with PBS solution, covered with immersion oil and 200 a sperm cells were evaluated for intact and damaged acrosome under a fluorescence microscope (Olympus Corporation BX 51FT, Tokyo, Japan).

The data were analysed with version 9.4 of Statistical Analysis System (SAS Institute, Inc., Cary, North Carolina, USA). The linear model was that of a $2 \times 4$ factorial analysis of variance as implemented in the GLM procedure. Duncan's multiple range test was used to compare means and declaring them different at a probability level of $P=0.05$.

\section{Results and Discussion}

In comparison with fresh semen, semen that was frozen and evaluated after being thawed had significantly reduced TM, PM, RM, VCL, VSL and VAP $(P<0.05)$ when evaluated with the CASA system (Table 1). Semen that was extended with egg yolk incorporated in the extender had significantly higher TM, PM, RM, VCL, VSL and VAP $(P<0.05)$ than that without egg yolk in the extender. The supplementation of PC liposome in extender with or without egg yolk did not improve the TM, PM, RM, VCL, VSL and VAP of the sperm cells $(P>0.05)$.

Freezing and thawing semen significantly reduced the percentage of live spermatozoa and the integrity of the sperm membrane and its acrosome $(P<0.05)$ relative to fresh semen (Table 2$)$. The frozenthawed treatments did not differ significantly $(P>0.05)$ on the percentage of live spermatozoa. Freezing and thawing semen in extender with egg yolk resulted in better membrane integrity compared with semen that was frozen in extender without egg yolk $(P<0.05)$. Integrity of the sperm cell membrane after freezing and thawing was not influenced by $P C$ liposome supplementation of the extender $(P>0.05)$. Supplementation of the extender that contained egg yolk with $\mathrm{PC}$ liposome did not improve the integrity of the acrosome $(P$ $>0.05$ ). Interestingly, supplementation of the extender without egg yolk with $0.75 \mathrm{mg} / \mathrm{ml}$ PC liposome resulted in acrosome integrity that was not significantly different $(P>0.05)$ from the treatments with egg yolk. 
Table 1 Effects of concentration of phosphatidylcholine-liposome supplementation to Tris-based extender with and without egg yolk on motility of Bapedi ram semen following cryopreservation

\begin{tabular}{|c|c|c|c|c|c|c|c|}
\hline & & TM, \% & PM, \% & $\mathrm{RM}, \%$ & $\mathrm{VCL}, \mu \mathrm{m} / \mathrm{s}$ & $V S L, \mu \mathrm{m} / \mathrm{s}$ & $\mathrm{VAP}, \mu \mathrm{m} / \mathrm{s}$ \\
\hline \multicolumn{2}{|c|}{ Fresh semen } & $91.3 \pm 2.9^{a}$ & $35.9 \pm 3.1^{a}$ & $49.7 \pm 7.9^{a}$ & $115.8 \pm 9.9^{a}$ & $71.2 \pm 7.1^{\mathrm{a}}$ & $93.1 \pm 8.0^{\mathrm{a}}$ \\
\hline \multicolumn{8}{|c|}{$\mathrm{PC}-\mathrm{L}, \mathrm{mg} / \mathrm{mL}$} \\
\hline \multirow{4}{*}{$\begin{array}{l}\text { without } \\
\text { egg yolk }\end{array}$} & 0 & $30.6 \pm 7.9^{\mathrm{cd}}$ & $4.8 \pm 3.2^{c d}$ & $3.9 \pm 3.7^{c d}$ & $48.9 \pm 8.9^{b c}$ & $25.3 \pm 7.3^{\text {cde }}$ & $34.4 \pm 8.0^{\text {cde }}$ \\
\hline & 0.25 & $14.7 \pm 7.9^{d}$ & $1.4 \pm 3.2^{d}$ & $1.4 \pm 3.7^{d}$ & $43.5 \pm 8.9^{c}$ & $19.3 \pm 7.3^{\text {de }}$ & $26.0 \pm 8.0^{\mathrm{e}}$ \\
\hline & 0.50 & $22.6 \pm 7.9^{d}$ & $2.1 \pm 3.2^{d}$ & $0.6 \pm 3.7^{d}$ & $34.6 \pm 8.9^{c}$ & $15.8 \pm 7.3^{e}$ & $22.8 \pm 8.0^{e}$ \\
\hline & 0.75 & $19.9 \pm 9.7^{d}$ & $2.8 \pm 3.9^{d}$ & $1.2 \pm 4.5^{d}$ & $41.4 \pm 10.8^{c}$ & $21.2 \pm 8.9^{\text {cde }}$ & $28.2 \pm 9.8^{\mathrm{de}}$ \\
\hline \multirow{4}{*}{$\begin{array}{l}\text { with egg } \\
\text { yolk }\end{array}$} & 0 & $60.5 \pm 9.7^{b}$ & $17.6 \pm 3.9^{b}$ & $19.2 \pm 4.5^{\mathrm{b}}$ & $77.0 \pm 10.8^{b}$ & $45.6 \pm 8.9^{b c}$ & $61.3 \pm 9.8^{b c}$ \\
\hline & 0.25 & $60.9 \pm 7.9^{\mathrm{b}}$ & $23.4 \pm 3.2^{b}$ & $20.5 \pm 3.7^{b}$ & $76.4 \pm 8.9^{b}$ & $56.7 \pm 7.3^{\mathrm{b}}$ & $67.4 \pm 8.0^{\mathrm{b}}$ \\
\hline & 0.50 & $60.7 \pm 7.9^{\mathrm{b}}$ & $16.8 \pm 3.2^{b}$ & $14.2 \pm 3.7^{b c}$ & $65.3 \pm 8.9^{b c}$ & $44.4 \pm 7.3^{\mathrm{bcd}}$ & $54.8 \pm 8.0^{\mathrm{bcd}}$ \\
\hline & 0.75 & $53.0 \pm 7.9^{b c}$ & $13.5 \pm 3.2^{b c}$ & $12.9 \pm 3.7^{b c}$ & $63.8 \pm 8.9^{b c}$ & $36.9 \pm 7.3^{\text {bcde }}$ & $48.3 \pm 8.0^{\text {bcde }}$ \\
\hline
\end{tabular}

TM: total motility, PM: progressively motility, RM: rapid motility, VCL: curvilinear velocity, VSL: straight line velocity, VAP: average path velocity, PC-L: phosphatidylcholine liposome

a-e Means in the same column with a common superscript do not differ with probability $P=0.05$

Table 2 Effects of concentration of phosphatidylcholine-liposome supplementation to Tris-based extender with and without egg yolk on viability, membrane integrity and acrosome integrity of sperm cells from Bapedi rams following cryopreservation

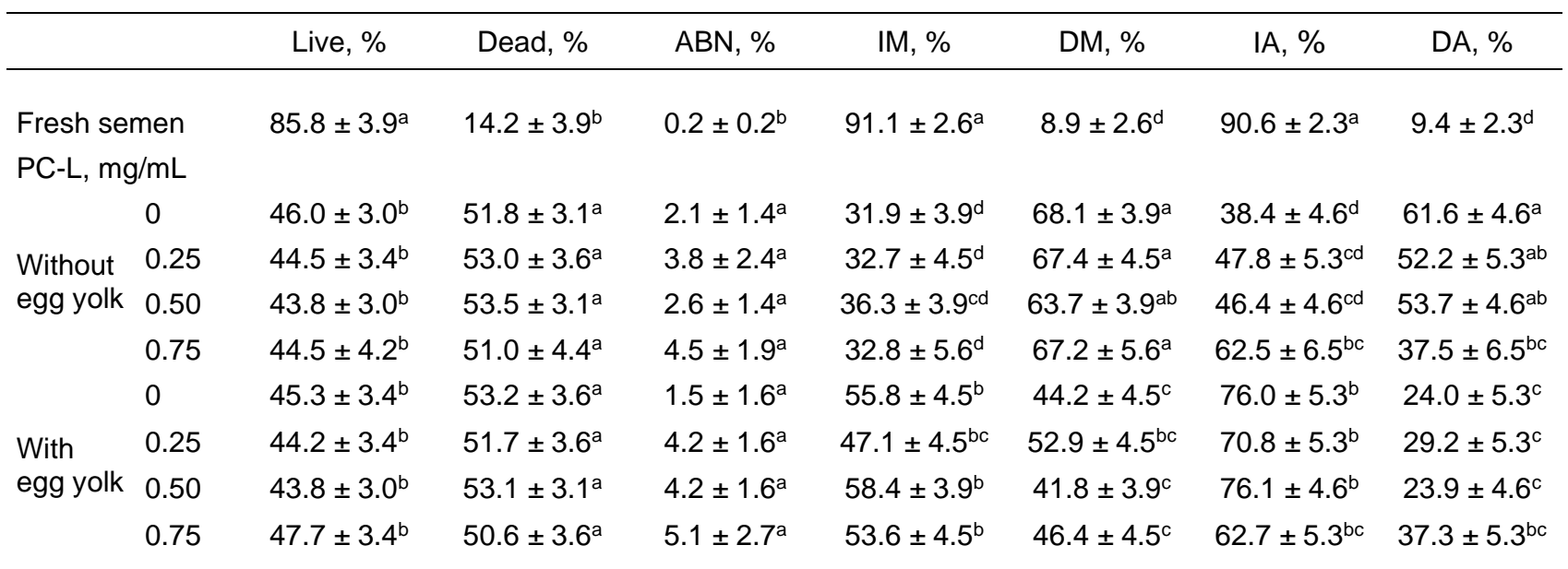

ABN: abnormal cells, IM: intact membrane, DM: damaged membrane, IA: intact acrosome, DA: damaged acrosome, PCL: phosphatidylcholine liposome

${ }^{a-d}$ Means in the same column with a common superscript do not differ with probability $P=0.05$

Bapedi sheep is a South African indigenous breed that has been reported to be under threat of extinction (Soma et al., 2012). Bapedi sheep can endure various climatic conditions and are tolerant to ticks and diseases (Soma et al., 2012). Cryopreservation of semen from Bapedi sheep is seen as a method of enabling their conservation.

The aim of this study was to evaluate the effect of PC as a cryoprotectant in extender with or without egg yolk on semen characteristics and acrosome integrity of sperm cells in semen from Bapedi rams that had been frozen and then thawed. The results demonstrated that supplementing PC liposome into Trisbased extender without egg yolk produced sperm that were less viable and had reduced motility compared with those that were cryopreserved in Tris-based extender with egg yolk. However, even the presence of egg yolk in the extender did not fully protect the spermatozoa against the detrimental effect of cryopreservation. This decline in semen quality after freezing and thawing is similar to the results of other studies (Forouzanfar et al., 2010; Luna-Orozco et al., 2019), and was, therefore, to be expected. 
The process of freezing semen subjects the sperm cells to chemical and structural alterations, resulting in compromised membrane integrity, viability and motility (Fukui et al., 2010). In the present study, frozen-thawed semen extended with egg yolk and without PC liposome resulted in higher sperm motility rates such as TM, PM, RM, VCL, VSL, and VAP compared with extender without egg yolk. The extenders containing egg yolk, with or without PC liposome were able to maintain the VCL, VSL and VAP of the spermatozoa, characteristics that have been linked to fertility (Del Olmo et al., 2013). The biochemical composition of egg yolk, which includes phospholipids, cholesterol and low-density lipoproteins, makes it an excellent cryoprotective ingredient of the extender used in freezing semen (Kulaksiz et al., 2010; Dong et al., 2011; Toker et al., 2016). But because the composition of egg yolk is variable and may carry pathogens, an alternative cryoprotective agent for use in freezing semen would be desirable. The present study evaluated the use of PC liposome for protection of the spermatozoa. However, the incorporation of PC liposome in extenders with or without egg yolk proved not to be beneficial for sperm motility.

Although semen freezing methodologies are generally similar across species, the success of cryopreservation depends on the species (Luna-Orozco et al., 2019) in part because of variations in size, shape, and lipid composition of spermatozoa (Purdy, 2006). Prior to the initiation of this study, it was anticipated that incorporation of PC liposome alone in the extender would improve the quality of cryopreserved ram semen, similarly to other species (He et al., 2001; Ropke et al., 2011; Pillet et al., 2012; Kumar et al., 2015). Murphy et al. (2018) found that whereas extenders that contained plant-based liposome significantly reduced post-thaw sperm motility and kinematics. However, this semen produced 60-day nonreturn rates in cattle that were similar to semen frozen in egg yolk-based extender. Luna-Orozco et al. (2019) also concluded that liposome-based diluents and those made with egg yolk produced similar results in terms of sperm parameters and were more efficient in protecting the integrity of membrane in freezing/thawing ovine semen. However, the incorporation of PC liposome in the extender was unable to protect ejaculated and epididymal sperm cells from boars compared with the use of $20 \%$ egg yolk in cryopreservation of their semen (Alvarez-Rodriguez et al., 2017).

The percentage of live spermatozoa in frozen-thawed semen was reduced in the present study regardless of whether the extender contained egg yolk and of the concentration of PC liposome. Similarly, Forouzanfar et al. (2010) found no significant differences in the percentage of live spermatozoa in ram semen cryopreserved with egg yolk and liposomes. Luna-Orozco et al. (2019) corroborated their results and found no effect of liposome or egg yolk extenders on the viability of frozen-thawed semen. However, Sitimurang (2012) observed significant differences on the percentage of live spermatozoa when the freezing bull semen was supplemented with PC liposome whether it included egg yolk or not.

Spermatozoa tend to become deformed during the initial stages of freezing, presumably as a consequence of water migrating into or out of the cells, leading to the organelles undergoing shrinkage and swelling (Ozkavukcu et al., 2008). Previously, the PC of egg yolk was considered the major cryoprotective agent of the sperm membrane against cold shock (Bergeron \& Manjunath, 2006; Forouzanfar et al., 2010). However, in the present study, the proportion of abnormal sperm cells increased after freezing and thawing, irrespective of the composition of the extender and the presence of PC-liposome in the extender without egg yolk did not protect the sperm membrane from damage. However, the use of liposomes has been shown to improve sperm membrane integrity to a degree that was not significantly different from egg yolk extender (Luna-Orozco et al., 2019).

The inability of the PC liposome to protect the sperm membrane remains difficult to assess, but the incubation period prior to freezing and the membrane phospholipid content of the semen might have played a role. Ropke et al. (2011) showed that the interaction of the sperm membrane and PC for 24 hours before freezing bovine semen resulted in improved membrane integrity. There are differences in the sperm membrane composition among species and breeds (Luna-Orozco et al., 2019). Previous studies assumed that $\mathrm{PC}$ is one of the major sperm membrane phospholipids and that it protects the membrane during freezing (Ricker et al., 2006; Zhang et al., 2009). Fang et al. (2016) noted that freezing changed the spermatozoa plasma membrane phospholipid profiles and functions, and the magnitude of the change was a function of the rate of freezing.

Acrosome integrity is an important component of sperm analysis to ensure fertility (Kumar et al., 2006). According to (Peruma, 2018), low acrosome integrity could lead to sperm cells with high motility that were not fertile. In the current study, the inclusion of $0.75 \mathrm{mg} / \mathrm{mL}$ PC liposome in extender without egg yolk surprisingly resulted in acrosome integrity that was similar to that achieved with Tris-based extender with egg yolk Similarly, during Buffalo semen cryopreservation, PC-liposome maintained the acrosome integrity to a degree that was similar to egg yolk extender (Kumar et al., 2015). Simpson et al. (1986) found that PC liposome has the ability to prevent the premature acrosome reaction, although no recent literature was found to corroborate that result. The acrosome reaction refers to the exocytotic process that occurs post the binding of the spermatozoa with the zona pellucida of the oocyte (Ickowics et al., 2012). Only spermatozoa 
with that have undergone the acrosome reaction can penetrate the zona pellucida and fertilize an oocyte (Avella \& Dean, 2011). Fertilization would be compromised if sperm cells had a premature acrosome reaction.

Lastly, the results of this study revealed that including the PC liposome in extender containing egg yolk did not improve semen quality. Although there are no previous records of PC liposome supplementation of egg yolk-based extenders for freezing ram semen, Sitimurang (2012) observed no beneficial effects on bull semen frozen using Tris-based extender with $10 \%$ egg yolk that was supplemented with $0 \mathrm{mg} / \mathrm{ml}$ and 0.5 $\mathrm{mg} / \mathrm{mL}$ PC liposome. This implies that supplementing relatively low levels of PC liposome in extender with egg yolk does not improve the quality of frozen-thawed semen. In a related study, contrary to the present results, Farshad et al. (2011) indicated that the inclusion of cholesterol-loaded-cyclodextrin in extenders with egg yolk improved the sperm quality compared with those without egg yolk. Their results might support the hypothesis of Purdy and Graham (2004) that the cholesterol that is supplemented in egg yolk extender is attracted to the egg yolk lipids instead of the sperm membrane. There is a possibility that in the current study the PC liposome was attracted to the lipids of the egg yolk instead of the sperm membrane, and thus did not benefit the sperm during freezing.

\section{Conclusions}

The supplementation of PC liposome in Tris-based extender is not a viable alternative for egg yolk in cryopreservation of ram semen. Sperm cell membrane integrity after thawing was not improved by supplementing extender with or without egg yolk with PC liposome. The addition of PC liposome in Trisbased extender with egg yolk yielded similar results to control (Tris-based extender with egg yolk alone) on sperm cell acrosome integrity. It is recommended that further studies should be undertaken to evaluate the effects of various phospholipid combinations and the protective mechanism of PC liposome on ram sperm cells if egg yolk is to be replaced in the semen extender.

\section{Acknowledgements}

The authors would like to acknowledge the parliamentary grant from the Agricultural Research Council for supporting the study.

\section{Authors' Contributions}

KSM collected the data for this study, analysed the data and wrote the initial draft of this manuscript; CMP collaborated in the interpretation of the results and drafting the manuscript; TC assisted in drafting the manuscript, and TLN interpreted the results and finalized the manuscript. All the authors approved the final version of the manuscript.

\section{Conflict of Interest Declaration}

None of the authors has any conflict of interest to declare.

\section{References}

Alcay, S., Toker, M.B., Gokce, E., Ustuner, B., Onder, N.T, Sigirkaya, H., Nur, Z. \& Soylu, M.K., 2015. Successful ram semen cryopreservation with lyophilized egg yolk-based extender. Cryobiology 71, 329-333.

Alcay, S., Ustuner, B. \& Nur, Z., 2016. Effects of low molecular weight cryoprotectants on the post-thaw ram sperm quality and freezing ability. Small Rumin. Res. 136, 59-64.

Alvarez-Rodriguez, M., Vicente-Carrillo, A. \& Rodriguez-Martinez, H., 2017. Exogenous individual lecithin phospholipids (phosphatidylcholine and phosphatidylglycerol) cannot prevent the oxidative stress imposed by cryopreservation of boar sperm. J. Vet. Med. Surg. 1, 1-11.

Amirat, L., Tainturier, D., Jeanneau, L., Thorin, C., Gérard, O., Courtens, J.L. \& Anton, M., 2004. Bull semen in vitro fertility after cryopreservation using egg yolk LDL: A comparison with Optidy $®$, a commercial egg yolk extender. Theriogenology 61, 895-907.

Avella, M.A. \& Dean, J., 2011. Fertilization with acrosome-reacted mouse sperm: Implications for the site of exocytosis. Proc. Natl. Acad. Sci. 108, 19843-19844.

Belala, R., Delay, J., Amirat, L., Marie-Hélène, R., Le Guillou, J., Marc, A., Schmitt, E., Thorin, C., Michaud, C., Kaidi, R.,

Tainturier, D. \& Bencharif, D., 2016. The benefits of liposome for chilling canine sperm for 4 days at $4{ }^{\circ} \mathrm{C}$. Anim. Reprod. Sci. $168,100-109$.

Bergeron, A. \& Manjunath, P., 2006. New insights towards understanding the mechanisms of sperm protection by egg yolk and milk. Mol. Reprod. Dev. 73, 1338-1344.

Castro, L.S., Hamilton, T.R.S., Mendes, C.M., Nichi, M., Barnabe, V.H., Visintin, J.A. \& Assumpção, M.E.O.A., 2016. Sperm cryodamage occurs after rapid freezing phase: flow cytometry approach and antioxidant enzymes activity at different stages of cryopreservation. J. Anim. Sci. Biotechno. 7, 1-9.

Chelucci, S., Pasciu, V., Succu, S., Addis, D., Leoni, G. G., Manca, M. E. \& Berlinguer, F., 2015. Soybean lecithin-based extender preserves spermatozoa membrane integrity and fertilizing potential during goat semen cryopreservation. Theriogenology 83, 1064-1074.

Day, J.G. \& Stacey, G.N., 2007. Cryopreservation and freeze-drying protocols. 2nd edition. Humana Press, New Jersey. pp. 39-50. 
Del Olmo, E., Bisbal, A., Maroto-Morales, A., García-Alvarez, O., Ramon, M., Jimenez-Rabadan, P., Martínez-Pastor, F., Soler, A.J., Garde, J.J. \& Fernandez-Santos, M.R., 2013. Fertility of cryopreserved ovine semen is determined by sperm velocity. Anim. Reprod. Sci. 138, 102-109.

Del Valle, I., Gomez -Duran, A., Holt, W.V., Muino-Blanco, T. \& Cebrian-Perez, J.A., 2012. Soy lecithin interferes with mitochondrial function in frozenthawed ram spermatozoa. J. Androl. 33, 717-725.

Dong, Q., Rodenburg, S.E., Hill, D.L. \& Vandevoort, C.A., 2011. The role of low-density lipoprotein (LDL) and highdensity lipoprotein (HDL) in comparison with whole egg yolk for sperm cryopreservation in rhesus monkeys. Asian J. Androl. 13, 459-64.

El-Sisy, G.A., El-Nattat, W.S., El-Sheshtawy, R.I. \& El-Maaty, A.A., 2016. Substitution of egg yolk with different concentrations of soybean lecithin in Tris-based extender during bulls' semen preservability. Asian Pac. J. Reprod. 5, 514-518.

Emamverdi, M., Zhandi, M., Shahneh, A.Z., Sharafi, M. \& Akbari-Sharafi, A., 2013. Optimization of ram semen cryopreservation using a chemically defined soybean lecithin-based extender. Reprod. Domest. Anim. 48, 899904.

Fang, Y., Blair, H., Zhong, R., Sun, H. \& Zhou, D., 2016. Optimizing the freezing rate for ovine semen cryopreservation: Phospholipid profiles and functions of the plasma membrane and quality and fertilization of spermatozoa. Small Rumin. Res. 139, 46-51.

Farshad, A., Amidi, F., Khor, A. \& Rashidi, A., 2011. Effect of cholesterol-loaded-cyclodextrin in presence and absence of egg yolk during freezing step on quality of Markhoz buck's spermatozoa. Asian-Austral. J. Anim. Sci. 24, 181-189.

Forouzanfar, M., Sharafi, M., Hosseini, S.M., Ostadhosseini, S., Hajian, M., Hosseini, L. \& Nasr-Esfahani, M.H., 2010. In vitro comparison of egg yolk-based and soybean lecithin-based extenders for cryopreservation of ram semen. Theriogenology 73, 480-487.

Fukui, Y., Kohno, H., Okabe, K., Katsuki, S., Yoshizawa, M., Togari, T. \& Watanabe, H., 2010. Factors affecting the fertility of ewes after intrauterine insemination with frozen-thawed semen during the non-breeding season. J. Reprod. Develop. 56, 460-466.

Grad, I., 2010. Liposome in gametes and embryo biotechnology. Ann. Anim. Sci. 10, 3-8.

Hernandez, P.J.E., Fernandez, R.F., Rodriguez, S.J.L., Juarez, R.E., Soto, M.Y.G. \& Garcia, R.A.D., 2012. Effect of cryopreservation of sheep semen related to its viability and acrosomal status. Rev. Sal. Anim. 34, 78-83.

Ickowicz, D., Finkelstein, M. \& Breitbart, H., 2012. Mechanism of sperm capacitation and the acrosome reaction: Role of protein kinases. Asian J. Androl. 14, 816-821.

Jerez, R., González, N., Olaciregui, M., Luño, V., de Blas, I. \& Gil, L., 2016. Use of soy milk combined with different cryoprotectants for the ram semen cryopreservation. Small Rumin. Res. 134, 34-38.

Jeyendran, R.S., Acosta, V.C., Land, S. \& Coulam, C.B., 2008. Cryopreservation of human sperm in a lecithinsupplemented freezing medium. Fertil. Steril. 90, 1263-1265.

Khalil, W.A., El-Harairy, M.A., Zeidan, A.E.B., Hassan, M.A.E. \& Mohey-Elsaeed O., 2018. Evaluation of bull spermatozoa during and after cryopreservation: Structural and ultrastructural insights. Int. J. Vet. Sci. Med. 6, 4956.

Khan, M.I.R. \& ljaz, A., 2008. Effects of osmotic pressure on motility, plasma membrane integrity and viability in fresh and frozen-thawed buffalo spermatozoa. Animal 4, 548-553.

Kulaksiz, R., Cebi, C., Akcay, E. \& Daskın, A., 2010. The protective effect of egg yolk from different avian species during the cryopreservation of Karayaka ram semen. Small Rumin. Res. 88, 12-15.

Kumar, N., Verma, R.P., Singh, L.P., Varshney, V.P. \& Dass, S.S., 2006. Effect of different levels and sources of zinc supplementation on quantitative and qualitative semen attributes and serum testosterone level in crossbred cattle (Bos indicus x Bos taurus) bulls. Reprod. Nutr. Dev. 46, 663-675.

Kumar. P., Saini, M., Kumar, D., Balhara, A.K., Yadav, S.P., Singh, P. \& Yadav, P.S., 2015. Liposome-based semen extender is suitable alternative to egg yolk-based extender for cryopreservation of buffalo (Bubalus bubalis) semen. Anim. Reprod. Sci. 159, 38-45.

Long, J.A. \& Conn, T.L., 2012. Use of phosphatidylcholine to improve the function of turkey semen stored at $4{ }^{\circ} \mathrm{C}$ for 24 hours. Poult. Sci. 91, 1990-1996.

Luna-Orozco, J. R., González-Ramos, M.A., Calderón-Leyva, G., Gaytán-Alemán, L.R., Arellano-Rodríguez, F., ÁngelGarcía, O. \& Véliz-Deras, F.G., 2019. Comparison of different diluents based on liposomes and egg yolk for ram semen cooling and cryopreservation. Iran. J. Vet. Res. 20, 126-130.

Matsuoka, T., Imai, H., Kohno, H. \& Fukui, Y., 2006. Effects of bovine serum albumin and trehalose in semen diluents for improvement of frozen thawed ram spermatozoa. Reprod. Fertil. Dev. 52, 675-683.

Munyai, P.H., 2012. Cryopreservation of South African indigenous ram semen. MSc dissertation, University of Free State, South Africa.

Murphy, E.M., O'Meara, C., Eivers, B., Lonergan, P. \& Fair, S., 2018. Comparison of plant- and egg yolk-based semen diluents on in vitro sperm kinematics and in vivo fertility of frozen-thawed bull semen. Anim. Reprod. Sci. 191, 7075.

Najafi, A., Najafi, M.H., Zanganeh, Z., Sharafi, M., Martinez-Pastor, F. \& Adeldust, H., 2014. Cryopreservation of ram semen in extenders containing soybean lecithin as cryoprotectant and hyaluronic acid as antioxidant. Reprod. Dom. Anim. 49, 934-940.

Ozkavukcu S., Erdemli E., Isik A., Oztuna D. \& Karahuseyinoglu, S., 2008. Effects of cryopreservation on sperm parameters and ultrastructural morphology of human spermatozoa. J. Assist. Reprod. Genet. 25, 403-411.

Peruma, P., 2018. Low density lipoprotein in cryopreservation of semen. Asian Pac. J. Reprod. 7, 103-116. 
Pillet, E., Labbe, C., Batellier, F., Duchamp, G., Beaumal, V., Anton, M., Desherces, S., Schmitt, E. \& Magistrini, M., 2012. Liposome as an alternative to egg yolk in stallion freezing extender. Theriogenology 77, 268-79.

Purdy, P.H. \& Graham, J.K., 2004. Effect of cholesterol-loaded cyclodextrin on the cryosurvival of bull sperm. Cryobiology 48, 36-45.

Purdy, P.H., 2006. A review on goat sperm cryopreservation. Small Rumin. Res. 63, 215-225.

Ricker, J.V., Linfor, J.J., Delfino, W.J., Kysar, P., Scholtz, E.L., Tablin, F., Crowe, J.H., Ball, B.A. \& Meyers, S.A., 2006. Equine sperm membrane phase behavior: the effects of lipid-based cryoprotectants. Biol. Reprod. 74, 359-365.

Rodriguez-Martinez, H. \& Barth, A.D., 2007. In vitro evaluation of sperm quality related to in vivo function and fertility. Soc. Reprod. Fertil. Suppl. 64, 39-54.

Ropke, T., Oldenhof, H., Leiding, C., Sieme, H., Bollwein, H. \& Wolkers, W.F., 2011. Liposome for cryopreservation of bovine sperm. Theriogenology 76, 1465-1472.

SAS. 2013. Proprietary software release 9.4. Statistical Analysis System Institute, Inc., Cary, North Carolina, USA.

Simpson, A.M., Swan, M.A. \& White, I.G., 1986. Action of Phosphatidylcholine in protecting ram sperm from cold shock. Gamete Res. 15, 43-56.

Singh, A.K., Singh, V.K., Narwade, B.M., Mohanty, T.K. \& Atreja, S.K., 2012. Comparative quality assessment of buffalo (Bubalus bubalis) semen chilled $\left(5^{\circ} \mathrm{C}\right)$ in egg yolk- and soya milk-based extenders. Reprod. Domest. Anim. 47, 596-600.

Situmorang, P., 2002. The effects of inclusion of exogenous phospholipid in Tris diluent with different level of egg yolk on the viability of bull spermatozoa. Indones. J. Anim. Vet. Sci. 7, 181-187.

Snyman, M.A., 2014. South African sheep breeds: Pedi Info-pack ref. 2014/025. Grootfontein Agricultural Development Institute.

Soma, P., Kotze, A., Grobler, J.P. \& Van Wyk, J.B. 2012. South African sheep breeds: Population genetic structure and conservation implications. Small Rumin. Res. 103, 112-119.

Toker, M.B., Alcay, S., Gokce, E. \& Ustuner, B., 2016. Cryopreservation of ram semen with antioxidant supplemented soybean lecithin-based extenders and impacts on incubation resilience. Cryobiology 72, 205-209.

Ugur, M.R., Saber Abdelrahman, A., Evans, H.C., Gilmore, A.A., Hitit, M., Arifiantini, R.I., Purwantara, B., Kaya, A. \& Memili, E., 2019. Advances in cryopreservation of bull sperm. Front. Vet. Sci. 6, 1-15.

Ustuner, B., Alcay, S., Nur, Z., Sagirkaya, H. \& Soylu, M.K., 2014. Effect of egg yolk and soybean lecithin on Tris-based extender in post-thaw ram semen quality and in vitro fertility. Kafkas Univ. Vet. Fak. Derg. 20, 393-398.

Vidal, A.H., Batista, A.M., Bento da Silva, E.C., Gomes, W.A., Pelinca, M.A., Silva, S.V. \& Guerra, M.M.P., 2013. Soybean lecithin-based extender as an alternative for goat sperm cryopreservation. Small Rumin. Res. 109, 4751.

Zhang, S.S., Hu, J.H., Li, Q.W., Jiang, Z.L. \& Zhang, X.Y., 2009. The cryoprotective effects of soybean lecithin on boar spermatozoa quality. Afr. J. Biotechnol. 8, 6476-6480. 